\title{
Innovation of Mathematics Teaching in Higher Vocational Colleges Based on Situated Cognition Theory
}

\author{
Haiying Qin, Yuqing Pan \\ Guangxi Technological College of Machinery and Electricity, Nanning City, Guangxi Province, 530007, \\ China
}

Keywords: Situated cognition theory, Higher vocational education, Mathematics teaching, Innovation.

\begin{abstract}
The traditional mathematics teaching in higher vocational colleges often ignores the connection between mathematics and the real world, and hinders the development of students' mathematical application ability and mathematical thinking consciousness. In view of this, Situated cognition theory is introduced into higher vocational mathematics teaching, which can improve the mathematics teaching model of higher vocational education and enhance the quality of mathematics teaching in higher vocational colleges. Based on the author's learning and practical experience, this paper firstly analyzed the main points of the theory of situated cognition, and then put forward the innovation model of higher vocational mathematics teaching based on this theory.
\end{abstract}

\section{Introduction}

Situated cognition theory attempts to correct cognitive errors in symbolic computing; in particular, it relies solely on the knowledge of rules and information descriptions. Situated cognition theory focuses only on conscious reasoning and cognitive thinking, ignoring the cultural and physical context of cognition. The situated cognition theory holds that practice is not independent of study, and meaning is not separated from practice and context, but it is negotiated in the context of practice and context. Knowledge is not a thing or a set of representations, nor is a collection of facts and rules. Knowledge is a dynamic construct and organization. It is an interactive state in the process of interaction between individuals and environment. It is also the ability of human beings to coordinate a series of behaviors and adapts itself to the environment of dynamic development. The crux of the traditional mathematics teaching in higher vocational colleges is that there is no close relation between the setting of the problem and the life and experience of the real world, and it can not help the students to think about the realistic situation and put forward and solve the real problems. Modern mathematics teaching attempts to create a real cognitive situation, which helps students to learn mathematics and apply mathematics in real situations by proposing and solving real and complex problems. This has become the same goal in the mathematics curriculum and teaching reform all over the world.

\section{Higher Vocational Mathematics Teaching Model Based on the "Situation - Problem"}

Mathematical situation design. The starting point of the "situation problem" mathematics teaching model is to design the mathematics situation, which can stimulate the motivation of study, urge the students to ask questions and guide the students' thinking actively. Therefore, the mathematics situation designed by teachers must have the following features: interest, guidance and rationality. In the "situation problem" mathematics teaching model, the following questions can be used to design a mathematical problem situation: firstly, we can design interesting questions through mathematical stories; second, we design knowledge problems with the formation and development of mathematical knowledge; thirdly, we design practical problems according to the practical value of mathematical knowledge; fourth, we design the "suspense" problem by setting suspense; fifth, we design activity-type problems through mathematical games and mathematical 
experiments.

Raising of mathematical problems. "Situation question" mathematics teaching pays great attention to students' autonomous participation learning and group cooperative learning in situated learning, and makes real and valuable interactions between teachers and students and interact with students with a special part of a mathematical instruction presented in mathematical problems. To create creative thinking and creative ability students, we need to have creative ability of mathematics teacher firstly. Educational scholars believe that creative teachers should focus on developing students' creative thinking ability and inspire students to find problems and ask them actively; teachers with creative ability must show great interest in students' questions and pay enough attention to them; for students' questions, creative teachers need not be eager to give answers, but they should inspire students to think independently with communicating and collaborating, so that to find the best solution.

In the "situation problem" mathematics teaching model, mathematics teachers need to solve the problem of how to help students to put forward mathematical problems and give solutions from the following five angles: first, the teacher wanted the students to ask the question type; second, the teacher inspired the students to put forward the way of asking questions; third, the teacher examines the reasonableness of the questions raised by the students; fourth, how do teachers deal with students' questions? Fifth, how do teachers inspire students to solve key questions? In the case of solving the above problems, mathematics teachers in mathematics teaching can stimulate students to put forward valuable mathematical problems, so that they can deal with students' mathematical problems flexibly. Further, mathematics teachers can properly arrange for students to communicate and interact with other students on solving the key problems, so that students can raise their awareness of mathematical problems and develop the ability to ask mathematical questions in the process of independent participation, interaction between teachers and students and group members assistance.

Solving to the mathematical problem. The process of students' mathematics problem awareness and the process of learning to solve mathematical problems are the processes of learning and experiencing creative mathematical activities. In the "situation - problem" mathematics teaching, we advocate the following mathematical problem-solving philosophy: firstly, mathematical problem solving activities should be carried out independently or collaboratively by the students in the mathematics situations set by the teacher; the teacher's help must be embodied in designing the best mathematics situation for the students, inspiring the students to question the questions and the students' mathematical thinking ability; second, the formation of creative thinking and ability should be reflected in the stages of posing mathematical problems, dealing with mathematical problems, the context of the design of questions, active studying, leading to mathematical problems, solving mathematical problems with questioning and thinking and finding similar mathematical problems. The formation of creative thinking and ability should be reflected in making deep thinking, questioning and drawing more profound mathematical problems on solved mathematical problems as a new situation. Thirdly, solving mathematical problems and posing mathematical problems should be carried out at the same time, so as to improve students' sense of problem and ability of innovation. For example, calculus teaching process is illustrated. In permitting conditions, we can complement the computer experimental mathematics; namely, we can compute the limit and mathematical calculations such as derivatives and integrals by using mathematical tools such as MATLAB; moreover, we also can draw a graph of a curve or surface, verify the theorems and discover new mathematical laws.

The application of mathematical knowledge based on situated cognition theory. The "situation problem" mathematics teaching model pays great attention to the practical application of students' mathematical knowledge, and emphasizes the independent study, mathematical problem setting and mathematical modeling of students from the designed mathematical situations. Teachers should have the ability to design mathematical situations that are closely related to students' real life in the course of applying the "situation problem" model to mathematics teaching, and inspire students to extract meaningful mathematical problem in the situation. At the same time, teachers 
should use the mathematical knowledge and mathematical thinking methods to construct corresponding mathematical models to solve the problem of their own settings. Therefore, "situation problem" of mathematical teaching not only focus on improving the students' ability of comprehensive application of mathematical knowledge to solve practical problems in mathematics, but also can improve the students' ability to produce the actual mathematical problems in the mathematical situations and improve students' comprehensive ability of using mathematical theory. For example, there is the engineering mathematics in higher vocational colleges. In studying ordinary differential equations, mechanical majors can relate to phenomena, such as mechanical vibrations; in the field of electrical engineering, Fu Liye series can be put forward according to signal analysis. According to the control theory, the mathematical problems related to Laplasse transformation are put forward; the expectation and variance of value at risk in economics and benefits of the insurance company can put forward the corresponding mathematical situation; at the same time, a problem will be put forward in the process of solving it; this kind of learning chain can also improve students' ability to raise and solve mathematical problems, and gradually cultivate students' keen interest in learning mathematics.

\section{Teaching Model of Higher Vocational Mathematics Based on Cognitive Apprenticeship}

This is proposed by educational researchers in view of the situation of knowledge. We conduct situated authentic teaching to students through this cognitive apprenticeship model. The method of cognitive apprenticeship tries to adapt students to the existing culture type in real practice by means of interaction with society. Cognitive apprenticeship supports learning in the field of reality, acquiring and developing and using cognitive tools through students' activities in the field of reality. This is similar to the apprenticeship approach in crafting, which enables students to acquire and use cognitive tools through practice and social interaction in practice. The expert's method of teaching is the mainly demonstration and guidance. Students acquire skills by combining their observation, imitation and expert guidance. In this process, students pay more attention to the reasoning process and cognitive strategy used by experts to complete their knowledge and experience according to their tasks, and to accomplish complex real tasks. This kind of teaching will help the learner to internalize and develop the skills of self guidance and self correction, and it is also suitable for the study of cognitive subjects in school. Mathematics learning requires the mathematics teacher to provide the corresponding cognitive strategy, thus it helps the student to carry on the inquiry mathematics study; at the same time, it allows students to follow certain rules in the mathematical ocean.

In the course of mathematics learning, students can form mathematics study groups with the help of mathematics teachers. For example, the platform is not set in the classroom, and each of the ten students formed a fixed group of mathematics learning in mathematics classroom teaching in the process of mathematics teaching; in the mathematics class, the members of the group communicate and compete with each other serving as the masters of the class. Mathematics teachers can design mathematics situations and guide them actively. The theoretical teaching time is less than ten minutes. This can improve students' interest in mathematics, stimulate their thinking and create a good atmosphere in class. In the course of mathematics teaching, they can provide students with many opportunities to observe the actual mathematical problems if we use video files to provide students with mathematical problem situations, so as to arouse students' cognitive conflict; if we use the mathematics experiment situation, we must make the students have the opportunity to operate by themselves. In the course of students' mathematics learning, the math teacher should help the students to work in the right direction as an expert if students have problems that can not be solved.

\section{Summary}

The design of mathematics teaching situation requires that mathematics teachers collect a lot of relevant mathematical information and summarize mathematical knowledge and methods. Designing the mathematics teaching situation that the teaching material conforms to, guides the 
student's study interest and adjusts the student's emotion to the best state. Thus, it can greatly improve the classroom teaching effect. Situated cognition theory provides a theoretical basis and practical method of operation for mathematics teaching activities. It is difficult for students to study mathematics. However, teachers must try their best to create the best situated cognition environment for students, so that students can learn math easily in a pleasant mood while interacting with students and situations.

\section{References}

[1] Xiong Shengxin. Research on Situated Cognition Theory in Higher Vocational Mathematics Teaching[J/OL]. Contemporary Educational Practice and Teaching Research: 1-3.

[2] Wang Ying. Preliminary Exploration of Mathematics Situated Teaching in Higher Vocational Education[J]. Manager, 2015, (35): 486.

[3] Ren Liya. Research on the Application of Situated Cognition Theory in Higher Vocational Mathematics Teaching[J]. Intellect, 2015, (29): 89.

[4] Ge Yu. Research on Improving the Effectiveness of Mathematics Situated Teaching in Higher Vocational Education[J]. Quality Education in Western China, 2015, (12): 51+53.

[5] Shi Lei. Design Concept and Principle of Situated Teaching in Higher Vocational Mathematics Teaching[J]. Jiannan Literature (Classic Teaching Home), 2013, (04): 383.

[6] Ma Ying. Research on the Application of Situated Cognition Theory in Higher Vocational Mathematics Teaching[J]. Vocational Education Forum, 2010, (30): 60-62.

[7] He Tao. Emotion Teaching and Situated Creation in Higher Vocational Mathematics[J]. China Vocational and Technical Education, 2010, (23): 20-22. 